\title{
A Review Study on Dengue Fiver in Dhaka City, Bangladesh
}

Dr. Muhammad Babul Miah" ${ }^{1 *}$, Dr. Mohammed Abu Shoeb Talukder ${ }^{2}$, Professor Dr. Ayesha Rafiq Chowdhury ${ }^{3}$, Dr. Tasrina Shamnaz Samdani ${ }^{4}$

${ }^{1}$ Assistant Professor, Department of Medicine, Enam Medical College and Hospital, Savar, Bangladesh

${ }^{2}$ Consultant, Department of Internal Medicine, Sheikh Fazilatunnessa Mujib Memorial KPJ Specialized Hospital \& Nursing College, Gazipur, Bangladesh

${ }^{3}$ Professor and Head of the Department, Department of Cardiology, Rakib Rabeya Medical College and Hospital, Sylhet, Bangladesh

${ }^{4}$ Associate Professor, Department of Medicine, Enam Medical College and Hospital, Savar, Bangladesh

DOI: $10.36347 /$ sjams.2021.v09i01.004

| Received: 19.10.2020 | Accepted: 03.11.2020 | Published: 04.01.2021

*Corresponding author: Dr. Muhammad Babul Miah

\section{Abstract}

Original Research Article

Background: Dengue is an acute fever caused by a mosquito-borne single stranded RNA positive-strand virus of the family Flaviviridae (DENV). Dengue fever is marked by the onset of sudden high fever, headache and ache behind the eyes, muscles and joints. In other form of dengue fever known as dengue heamorrhagic fever (DHF) symptoms of bleeding usually occur after 3-5 days of fever. City with high density of population like Dhaka city is a fertile area for dengue transmission. Objective of the study: The objective of this study was to assess the dengue fever transmission situation in Dhaka city of Bangladesh. Materials \& Methods: This study was a review study on several studies conducted during the recent years regarding dengue fever as well as dengue heamorrhagic fever. A wide range of published articles were studied and analyzed in this intervention. All the data were analyzed and displayed by several tables as well as charts of MS Office program. Results: Most alarming finding was, the number of patients from urban and rural areas were near about equal. In that study patients from village was 54\% and patients from city and semi town areas were $19.4 \%$ and $26.6 \%$ respectively. The number of patients with dengue fever of students and housewives were greater than that of any other professional group. In another study it was found that, $28.7 \%$ participants were with primary and $71.3 \%$ were with secondary infection of dengue. Conclusion: According to the findings of several studies on dengue and dengue hemorregic fiver conducted in Bangladesh and abroad we found season, information regarding this diseases, treatment infrastructure and diagnostic facilities are important component in dengue issue.

Keywords: Dengue hemorregic fever (DHF), transmission, aedes aegypti, Dhaka, mosquito.

Copyright $(\mathcal{C} 2021$ The Author(s): This is an open-access article distributed under the terms of the Creative Commons Attribution 4.0 International License (CC BY-NC 4.0) which permits unrestricted use, distribution, and reproduction in any medium for non-commercial use provided the original author and source are credited.

\section{INTRODUCTION}

Dengue is an acute fever caused by a mosquito-borne single stranded RNA positive-strand virus of the family Flaviviridae (DENV). Dengue fever is marked by the onset of sudden high fever, headache and ache behind the eyes, muscles and joints. In other form of dengue fever known as dengue haemorrhagic fever (DHF) symptoms of bleeding usually occur after 3-5 days of fever. Annually, approximately 390 million dengue infections are estimated to occur, of which a quarter of the cases (67-136 million) will manifest clinically [1], with the overall incidence of dengue having increased 30 -fold over the past 50 years [2]. The first documented dengue epidemic occurred in the 1780 s, and was recorded almost simultaneously in Asian, African, and North American regions [3]. On the other hand, in Asia, a severe dengue outbreak was reported in the 1950s in the Philippines and Thailand, ${ }^{2}$ and in 1964 Bangladesh experienced a dengue outbreak for the first time, at which time the name dacca fever was coined. Sporadic cases and small outbreaks clinically suggestive of dengue occurred across the country between 1964 and 1999, but not reported officially, even though 5551 people were affected with 93 accounted fatalities [4]. In this same study it was also claimed that, the first official outbreak of dengue fever in Bangladesh was in 2000, and since then the number of hospitalized patients has exceeded 3000, 6232 in 2002, 3934 in 2004, 3162 in 2015, 6060 in 2016, 10148 in 2018, and 100 112, 000 cases by the end of 2019 [4]. As national surveillance is passive and only government hospitals are included, it is like highly that substantial under-reporting is taking place. Besides this, the operational surveillance is not based on appropriate methods, such as the WHO projection done in July, 2019, where an estimated 358,960 people were deemed to be infected compared with only 7179 cases 
in official reports [5]. At that time it was claimed that, based on the aforementioned official number of cases in November, 2019, as many as 3-4 million people could have conceivably been affected. Besides these, about dengue situation of 2000 in a study they claimed, "the country is facing its worst dengue outbreak since 2000, with fears of mortality running deep as the infection reaches all parts of the country, particularly affecting children, pregnant women, and older people [6]. In 2018, 10,148 dengue cases were reported, 6 and as of Aug 23, 2019, 59,592 people have been infected, with 47 confirmed deaths (the unofficial death toll is 111) [7]. Poor water management, inadequate sanitation and hygiene systems, alongside a dense population, are prolonging the outbreak in Bangladesh. Before 2000, only sporadic dengue cases were reported from Dhaka and other parts of the country [8]. In fact, dengue caused a serious public health concern, following a sudden outbreak in 2000 where around 5,551 cases and 93 deaths occurred in Bangladesh. Both types of the vectors (Aedes aegypti and Aedes albopictus) were identified in Bangladesh, during the dengue outbreaks from 2000-2017 [9] Due to due to chikungunya viruses, re-emergence of dengue and the recent emergence of the disease both spread by the Aedes mosquitoes. This are very worrying and have created a huge burden in morbidity and mortality with insufficient allocation of resources under the CDC Operational Plan of the Health, Population, and Nutrition Sector Program (HPNSP: 2017-2022) [10]. A foretaste of the dengue situation in Southeast Asia can provide a picture of how this emerging disease is causing a huge economic and social burden in Southeast Asia, particular Bangladesh, in specific [11]. Dengue situation in Bangladesh is creating economic burden in health sector as the allocation of health budget is gradually declining by year and the out-of-pocket expenditures (OOPs) are increasing (67\%), which is highest in the Southeast Asia region) according to the study findings of Bangladesh National Health Accounts (BNHA-V) [12]. The Health Sector Plan in Bangladesh, 4th Health, Population and Nutrition Sector Program (HPNSP: 2017-2022) [13], aims to ensure a quality and equitable health care for the entire population by improving their access to assured quality care, particularly by the poor, women, as well as children. CDC (Centers for Diseases Control and Prevention) is one of the active units of the Directorate General of Health Services (DGHS) under the Ministry of Health and Family Welfare (MoHFW) of the country. Until 1999, all the activities of CDC were attached to the Directorate of Primary Health Care (PHC) and were delivered by a Deputy Director, CDC. The outbreak of dengue in Dhaka city area in 2000, centers for diseases control and prevention as an independent unit under disease control division of DGHS to cope with the emergency management crisis of the dengue situation in the Ministry of Health and Family Welfare. CDC was established to communicable dengue situations throughout country, so that, it can never be a serious public health issue for the people of
Bangladesh. Presently, the CDC has seven components under its Operational Plan (OP) in the HPNSP, where Aedes mosquito-borne diseases such as dengue, chikungunya, and zika remain as sub-components under the Malaria Elimination Control Program [14].

\section{OBJeCtives \\ General Objective}

- To assess the dengue fever transmission situation in Dhaka city of Bangladesh.

\section{Specific Objective \\ - To evaluate the socio-demographic characteristics of dengue fever in Bangladesh}

\section{Materials \& Methods}

This study was a review study on several studies conducted during the recent years regarding dengue fever as well as dengue Haemorrhagic fever. A wide range of published articles were studied and analyzed in this intervention. For this review study only the articles regarding recent researches were considered. As our study was based on dengue transmission in Dhaka so we had given more emphasis on that studies which was conducted upon the dengue issue of Dhaka or Bangladesh. Some other foreign studies were studied and mentioned herewith which was much related to our issue or important regarding technical and referral factors. We found some dissimilarities among several studies in some vital and mostly less potential issues. In generally we had avoided those data in analyzing. Mostly we have taken those data which was supported or gathered by maximum articles of studies. All the data were analyzed and displayed by several tables as well as charts of MS Office program.

\section{RESULTS}

In a recent study 2020 [16] we found that, patients of both gender were affected by dengue fever equally. Male were $50.10 \%$ whereas female was $49.90 \%$. The highest number of cases were found from $16-30$ years' age group which was $54.60 \%$. Then $24.7 \%, 12.3 \%, 4.8 \%$ and $3.8 \%$ patients were found from $31-45,46-60,>60$ and 1-15 years' age groups respectively. Most alarming finding was, the number of patients from urban and rural areas were near about equal. In that study [16] patients from village was 54\% and patients from city and semi town areas were $19.4 \%$ and $26.6 \%$ respectively. It was also found that, $12.6 \%$, $17 \%, 25.5 \%, 22.5 \%, 17.8 \%$ and $4.6 \%$ patients of that study were illiterate, primary level educated, secondary level educated, intermediated level educated graduate and post graduate respectively. In that study patients from several professions were found. Such as service holder $(8.7 \%)$, teacher $(7.4 \%)$, businessmen $(10.6 \%)$, farmer $(5.2 \%)$, student $(34.4 \%)$, laborer $(4.9 \%)$, housewife $(21.1 \%)$, people with some irregular works (4\%) and other professions (3.8\%) were found. 
Muhammad Babul Miah et al; Sch J App Med Sci, Jan, 2021; 9(1): 21-27

However, the number of patients of students and housewives were greater than that of any other professional group. In the same study it was also found that, $40.7 \%, 34.1 \%, 18.5 \%$ and $6.7 \%$ patient were from $<15,000,<30,000,<50,000$ and $>50,000$ Taka/month income groups. According to the socio-economic status of that study it was also found that, $16.1 \%, 30 \%, 46.9 \%$ and $6.9 \%$ patients were from lower, lower middle, middle and upper middle class families. In a study [17] according to their presentation (Figure-1) during the period from 2010 to 2014 most of the cases of dengue were from 20-34 years' age group. The aged patients found in less numbers with dengue fever. In another study [18] it was found that, $28.7 \%$ participants were with primary and $71.3 \%$ were with secondary infection of dengue. Among primary level infected people (28.7\%), 20.7\% were adult and $8 \%$ were children. On the other hand, among secondary level infected people (71.3\%), 61.5\% were adult whereas $9.8 \%$ were children. In that study it was also found that, among total 174 participants $104(59.77 \%)$ were with dengue fever, $69(39.66 \%)$ were with dengue hemorrhagic fever and 01 was with dengue shock syndrome.

Table-1: Socio-demographic characteristics of dengue fever in Bangladesh [16]

\begin{tabular}{|c|c|c|}
\hline Characteristics & $\mathrm{n}(\%)$ & $95 \% \mathrm{CI}$ \\
\hline \multicolumn{3}{|l|}{ Gender } \\
\hline Male & $506(50.1)$ & \multirow[t]{2}{*}{$1.47-1.53$} \\
\hline Female & $504(49.9)$ & \\
\hline \multicolumn{3}{|l|}{ Age } \\
\hline $1-15$ & $38(3.8)$ & \multirow{3}{*}{$2.54-2.65$} \\
\hline $16-30$ & $551(54.6)$ & \\
\hline $31-45$ & $249(24.7)$ & \\
\hline $46-60$ & $124(12.3)$ & \\
\hline$>60$ & $48(4.8)$ & \\
\hline \multicolumn{3}{|l|}{ Living place } \\
\hline Village & $545(54.0)$ & \multirow{3}{*}{$1.61-1.70$} \\
\hline Semi Town & $269(26.6)$ & \\
\hline City & $196(19.4)$ & \\
\hline \multicolumn{3}{|l|}{ Literacy status } \\
\hline Illiterate & $127(12.6)$ & \multirow{6}{*}{$3.21-3.38$} \\
\hline Primary & $172(17.0)$ & \\
\hline Secondary & $258(25.5)$ & \\
\hline Intermediate & $227(22.5)$ & \\
\hline Graduate & $180(17.8)$ & \\
\hline P. Graduate & $46(4.6)$ & \\
\hline \multicolumn{3}{|c|}{ Employment status } \\
\hline Job holder & $88(8.7)$ & \\
\hline Teacher & $75(7.4)$ & \multirow{7}{*}{$4.78-5.04$} \\
\hline Businessman & $107(10.6)$ & \\
\hline Farmer & $53(5.2)$ & \\
\hline Student & $347(34.4)$ & \\
\hline Laborer & $49(4.9)$ & \\
\hline Housewife & $213(21.1)$ & \\
\hline Others & $38(3.8)$ & \\
\hline Irregular & $40(4.0)$ & \\
\hline \multicolumn{3}{|c|}{ Family income (Taka/month) } \\
\hline$<15,000$ & $411(40.7)$ & \multirow{4}{*}{$1.86-1.97$} \\
\hline$<30,000$ & $344(34.1)$ & \\
\hline$<50,000$ & $187(18.5)$ & \\
\hline$>50,000$ & $68(6.7)$ & \\
\hline \multicolumn{3}{|c|}{ Socio economic status } \\
\hline Lower & $163(16.1)$ & \multirow[t]{4}{*}{$2.39-2.50$} \\
\hline Lower middle & $303(30.0)$ & \\
\hline Middle & $474(46.9)$ & \\
\hline Upper middle & $70(6.9)$ & \\
\hline
\end{tabular}




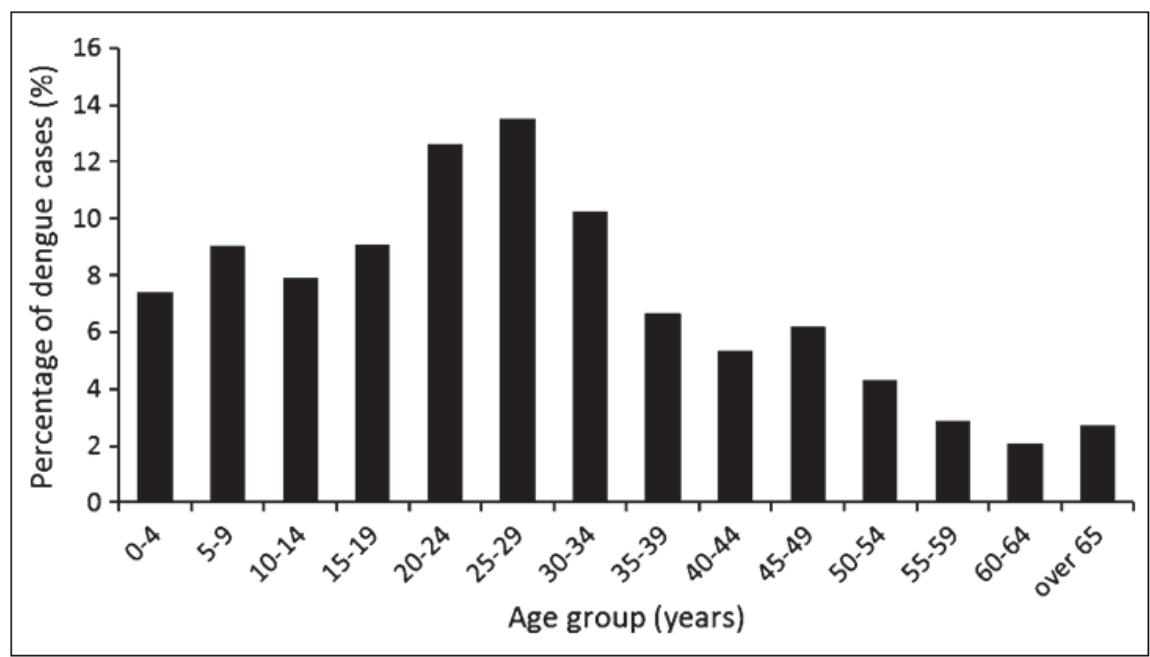

Fig-1: Age distribution of dengue cases for the period 2010-2014. Percentage of dengue cases in each age category over the entire study period [17]

Table-2: Distribution of serologically positive dengue cases by type of infections in adults and children, Bangladesh, 2000 [18]

\begin{tabular}{|l|l|l|l|l|}
\hline $\begin{array}{l}\text { Type of Infection, by } \\
\text { age group }\end{array}$ & $\begin{array}{l}\text { Dengue fever } \\
(\mathbf{n = 1 0 4 )}\end{array}$ & $\begin{array}{l}\text { Dengue hemorrhagic fever } \\
(\mathbf{n = 6 9 )}\end{array}$ & $\begin{array}{l}\text { D. Shock Syndrome } \\
(\mathbf{n = 1})\end{array}$ & $\begin{array}{l}\text { Total cases } \\
(\mathbf{n = 1 7 4 )}\end{array}$ \\
\hline Primary & $39(37.5)$ & $11(15.9)$ & $0(0.0)$ & $50(28.7)$ \\
\hline Adults & $26(25.0)$ & $10(14.5)$ & $0(0.0)$ & $36(20.7)$ \\
\hline Children & $13(12.5)$ & $1(1.4)$ & $0(0.0)$ & $14(8.0)$ \\
\hline Secondary & $65(62.5)$ & $58(84.1)$ & $1(100)$ & $124(71.3)$ \\
\hline Adults & $55(52.9)$ & $51(73.9)$ & $1(100)$ & $107(61.5)$ \\
\hline Children & $10(9.6)$ & $7(10.2)$ & $0(0.0)$ & $17(9.8)$ \\
\hline
\end{tabular}

${ }^{\mathrm{a}}$ Adults $>18$ yrs of age; children $<18$ yrs of age.

${ }^{\mathrm{b}}$ Two cases that were negative by enzyme-linked immunosorbent assay and positive by reverse transcription-polymerase chain reaction were not included.

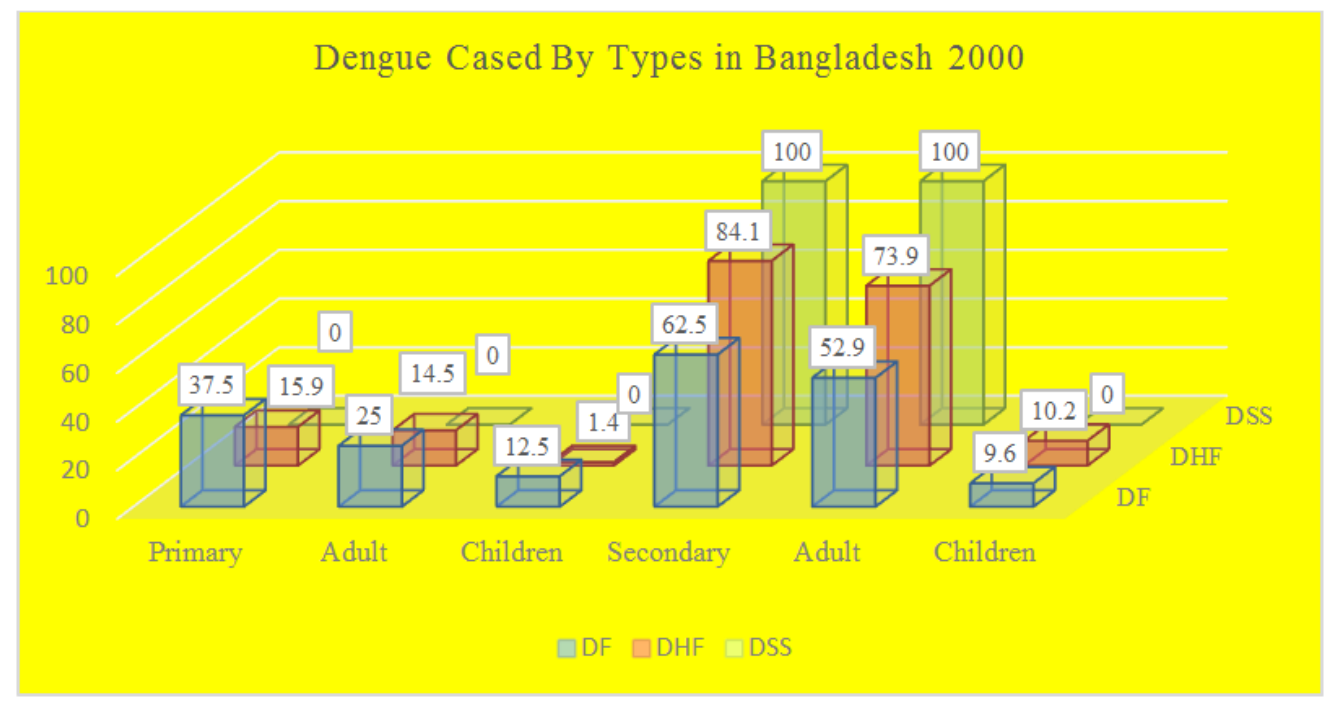

Fig-2: Dengue Cases by Types of Infection 2000 in Bangladesh

\section{DiscUSSION}

Over population, impromptu and uncontrolled urbanization are identified as the key factor for increasing transmission of mosquito-borne diseases like dengue [19]. For dengue epidemics and control; KAPs among the population could be played a critical role
[20] to It was revealed that lack of knowledge about clinical features or control measures is the most common problem, to control the dengue virus [21]. Among the study population with poor knowledge of symptoms associated with DF, the disease might easily be confused with other common causes of fever such as influenza and typhoid22 even COVID-19. Dengue 
causes more illness and death than any other arboviral infection in the world [23]. This first epidemic highlights the geographic expansion of DHF in Bangladesh, where classic DF caused by multiple serotypes had been previously reported [24]. The dengue hemorregic fiver outbreak started in late June 2000, peaked in September of rainy season and subsided in the dry winter season in December 2000. Though dengue affected all age groups, adults predominated in this hospital. In Singapore, India, Malaysia, and Brazil, where dengue has been epidemic for several years, the mean age of dengue infection is increasing and adults are frequently infected which indicating an epidemiologic change in dengue infection in those locations [25]. The accurate measure of this countrywide outbreak is unknown; 5, 575 hospitalized dengue cases were reported to the Ministry of Health in Bangladesh, with a case-fatality rate of $1.61 \%$ through mid-November 2000 [26]. Most patients had DF, 25\% with bleeding manifestations (a severe form of the illness) [23]. WHO (World Health Organization) classification of dengue diseases is often not feasible in many countries because of lack of trained health professionals, adequate laboratories, and radiologic support. The facilities to detect dengue hemorregic fiver (DHF) by using hematocrit (capillary method) and plasma leakage signs (chest radiograph or ultra- sound) are not readily available in many tropical countries. Effective treatment of dengue depends on symptom recognition and careful fluid management [27]. Such a diffident classification of dengue diseases based on signs and symptoms is needed to progress case management and decrease deaths. DHF is believed to happen as a result of antibody-dependent heightening of heterotypic-secondary dengue infections [23]. The incidence of dengue fever in Bangladesh show a marked seasonal variation, although this is becoming less marked in most recent years. Most of the studies have shown that, most dengue cases occur in the monsoon and post-monsoon season. Seasonal variation based similar dengue cases in Dhaka city were reported by a study of Karim and Morales et al., [28]. The season-specific concentration of dengue cases was well reported in many other similar studies in Southeast Asia and other countries [29]. The findings of our study on seasonal variation also matched in the adjacent geographical locations of Myanmar and India [31]. Last fourteen years in the pre-monsoon season of 20002014 , for a negligible number of cases were reported. However, since 2015, the dengue cases started to be reported from the early part of the year in 2015-2017, the number of dengue cases reported in the premonsoon season is 7 times higher than those reported in the previous 14 years [30]. In addition, in the early part of the year 2018, a dengue death occurred in the premonsoon season for the first time in Bangladesh and highest number of cases $(10,148$; although very relevant but not included in the study due to study time frame) were reported within last 18 years (Source: Control Room, DGHS), which is also in support of the study hypothesis. Our findings corroborate the findings of other similar studies in many other countries in the same geographical regions [31]. Our study showed that the rise of average temperature was also linked to increased dengue infection at the same time. It is known that temperature increases lead to expansion of the area involved and the number of cases of vector-borne diseases [32]. Similarly, the present study showed a highly significant correlation with humidity and the increase in dengue cases. These conditions facilitate the growth and survival of mosquitoes needed for successful propagation of the virus in the environment [33]. The impact of climate on an increased dengue case reporting is suggested by other similar studies [34]. The longitudinal distribution signified the density of Aedes aegypti and the larval indices, which were moderately high in Dhaka city and encouraged all the stakeholders to take immediate action as in other countries [35]. In a survey findings, the important reservoirs of vectors are almost same in Southeast Asian countries [36]. It would be very interesting to know whether the whole period of 2017, the vector Aedes mosquitoes carried either dengue or chikungunya virus or both. Chen et al., found both dengue and chikungunya infection at the same time among travelers [37].

\section{CONCLUSiON AND RECOMMENDATIONS}

According to the findings of several studies on dengue and dengue hemorragic fiver conducted in Bangladesh and abroad we found season, information regarding this diseases, treatment infrastructure and diagnostic facilities are important component in dengue issue. For getting more specific findings our recommendation is to conducting more studies regarding the same issue.

\section{REFERENCES}

1. Bhatt S, Gething PW, Brady OJ, Messina JP, Farlow AW, Moyes CL, Drake JM, Brownstein JS, Hoen AG, Sankoh O, Myers MF. The global distribution and burden of dengue. Nature. 2013 Apr;496(7446):504-7.

2. WHO. Dengue fact sheet. http://www.searo. who.int/entity/vector_

borne_tropical_diseases/data/data_ factsheet /en/ (accessed Sept 9, 2019).

3. Dengue Virus Net. History of dengue. http://www.denguevirusnet.com/historyofdengue.html (accessed Sept 9, 2019).

4. Sharmin S, Viennet E, Glass K, Harley D. The emergence of dengue in Bangladesh: epidemiology, challenges and future disease risk. Trans R Soc Trop Med Hyg. 2015; 109:619-27.

5. Prothom A. The number of dengue victims has increased by three and a half million. 2019. https://www. prothomalo.com /bangladesh / 
article/1605652/ (accessed Sept 9, 2019; in Bangla).

6. Alam H. Dengue deaths so far: most were infected a second time. 2019. https://www. thedailystar.net/frontpage/max-people-dieddengue-fever-in-bangladesh-infected-forsecond-time-1782226 (accessed Sept 23, 2019).

7. Alam H. Dengue outside Dhaka: non-critical patients crowd dist hospitals. 2019. https://www.thedailystar.net /frontpage/ denguesituation-in-bangladesh-non-critical- patientscrowd-dist-hospitals-1789174 (accessed Sept 23, 2019).

8. Russell PK, Buescher EL, McCown JM, Ordoñez J. Recovery of dengue viruses from patients during epidemics in Puerto Rico and East Pakistan. The American journal of tropical medicine and hygiene. 1966 Jul 1;15(4):573-9.

9. Ali M, Wagatsuma Y, Emch M, Breiman RF. Use of a geographic information system for defining spatial risk for dengue transmission in Bangladesh: role for Aedes albopictus in an urban outbreak. The American journal of tropical medicine and hygiene. 2003 Dec 1;69(6):634-40.

10. Guzman MG, Halstead SB, Artsob H, Buchy P, Farrar J, Gubler DJ, Hunsperger E, Kroeger A, Margolis HS, Martínez E, Nathan MB. Dengue: a continuing global threat. Nature reviews microbiology. 2010 Dec;8(12):S7-16.

11. Shepard DS, Undurraga EA, Halasa YA. Economic and disease burden of dengue in Southeast Asia. PLoS Negl Trop Dis. 2013 Feb 21;7(2):e2055.

12. Health Economics Unit, Bangladesh National Health Ac- counts (BNHA-V), 1997-2015, Ministry of Health \& Family Welfare, Dhaka, Bangladesh, 2015.

13. Ministry of Health \& Family Welfare, "Program imple- mentation plan (PIP)," in Proceedings of 4th Health, Pop- ulation and Nutrition Sector Programme (4th HPNSP), 2017-2022, Dhaka, Bangladesh, January 2017.

14. Directorate General of Health Services, Ministry of Health.

15. Family Welfare, "Operational plan (OP), communicable disease control (CDC)," in Proceedings of Health, Population and Nutrition Sector Programme, 2017-2022, Dhaka, Bangladesh, January 2017.

16. Hossain MI, Akter S, Suriea U, Akter S, Shifat SK, Islam MM, Aziz I, Islam MS, Mohiuddin AK. Knowledge, awareness and preventive practices of dengue outbreak in Bangladesh: a countrywide study. 2020.

17. Morales I, Salje H, Saha S, Gurley ES. Seasonal distribution and climatic correlates of dengue disease in Dhaka, Bangladesh. The American journal of tropical medicine and hygiene. 2016 Jun 1;94(6):1359-61.
18. Rahman M, Rahman K, Siddque AK, Shoma S, Kamal AH, Ali KS, Nisaluk A, Breiman RF. First outbreak of dengue hemorrhagic fever, Bangladesh. Emerging infectious diseases. 2002 Jul;8(7):738.-740.

19. Sharmin S, Viennet E, Glass K, Harley D. The emergence of dengue in Bangladesh: epidemiology, challenges and future disease risk. Transactions of The Royal Society of Tropical Medicine and Hygiene. 2015 Oct 1;109(10):619-27.

20. Dhar- Chowdhury P, Haque CE, Driedger SM. Dengue disease risk mental models in the city of Dhaka, Bangladesh: juxtapositions and gaps between the public and experts. Risk Analysis. 2016 May; 36(5):874-91.

21. Nguyen PV, Vo TQ, Nguyen TD, Chung TP, Ho NP. Dengue fever in Southern of Vietnam: A survey of reported knowledge, attitudes, and practices. JPMA. The Journal of the Pakistan Medical Association. 2019 Jun;69(6):S118-30.

22. Shuaib F, Todd D, Campbell-Stennett D, Ehiri J, Jolly PE. Knowledge, attitudes and practices regarding dengue infection in Westmoreland, Jamaica. West Indian Medical Journal. 2010 Mar; 59(2):139-46.

23. Gubler DJ. The global pandemic of dengue/dengue haemorrhagic fever: current status and prospects for the future. Ann Acad Med Singapore 1998; 27:227-34.

24. Russell PK, Buescher EL, McCown JM, Ordonez J. Recovery of dengue viruses from patients during epidemics in Puerto Rico and East Pakistan. Am J Trop Med Hyg. 1966; 15:573-9.

25. Goh KT. Changing epidemiology of dengue in Singapore. Lancet. 1995; 346:1098.

26. Amin MM, Hussain AM, Murshed M, Chowdhury IA, Mannan S, Chowdhury SA, Banu D. SearoDiagnosis of Dengue Infections by Haemagglutination Inhibition Test (HI) in Suspected Cases in Chittagong, Bangladesh. WHO Dengue Bull. 1999; 23:34-8.

27. World Health Organization. Dengue haemorrhagic fever: diagnosis, treat- ment, prevention and control (2nd edition). Geneva: World Health Organization; 1997.

28. Karim MN, Munshi SU, Anwar N, Alam MS. Climatic factors influencing dengue cases in Dhaka city: a model for dengue prediction. The Indian journal of medical research. 2012 Jul;136(1):32-39.

29. Lee HS, Nguyen-Viet H, Nam VS, Lee M, Won S, Duc PP, Grace D. Seasonal patterns of dengue fever and associated climate factors in 4 provinces in Vietnam from 1994 to 2013. BMC infectious diseases. 2017 Dec 1;17(1):218.

30. Victor TJ, Malathi M, Asokan R, Padmanaban P. Laboratory-based dengue fever surveillance in 
Tamil Nadu, India. Indian Journal of Medical Research. 2007 Aug 1;126(2):112-6.

31. Sharma RS, Panigrahi N, Kaul SM, Barua K, Bhardwaj M. Status Report on DF/DHF During 1998 in the National Capital Territory of Delhi, India. Dengue Bulletin, 1999; 23:109-112.

32. Schnoor JL. The IPCC fourth assessment. Environmental Science \& Technology, 2007; 41(5):1503.

33. Focks DA, Daniels E, Haile DG, Keesling JE. A simulation model of the epidemiology of urban dengue fever: literature analysis, model development, preliminary validation, and samples of simulation results. The American journal of tropical medicine and hygiene. 1995 Nov 1;53(5):489-506.

34. Wu PC, Guo HR, Lung SC, Lin CY, Su HJ. Weather as an effective predictor for occurrence of dengue fever in Taiwan. Acta tropica. 2007 Jul 1;103(1):50-7.

35. Barbosa GL, Donalísio MR, Stephan C, Lourenço RW, Andrade VR, de Brito Arduino M, de Lima VL. Spatial distribution of the risk of dengue and the entomological indicators in Sumaré, State of São Paulo, Brazil. PLoS Negl Trop Dis. 2014 May 15;8(5):e2873.

36. Nguyen LA, Clements AC, Jeffery JA, Yen NT, Nam VS, Vaughan G, Shinkfield R, Kutcher SC, Gatton ML, Kay BH, Ryan PA. Abundance and prevalence of Aedes aegypti immatures and relationships with household water storage in rural areas in southern Viet Nam. International Health. 2011 Jun 1;3(2):115-25.

37. Chen LH, Wilson ME. Dengue and chikungunya infections in travelers. Current opinion in infectious diseases. 2010 Oct 1;23(5):438-44. 